\title{
Diurnal variability of the planetary boundary layer height estimated from radiosonde data
}

\author{
Jie Gu' ${ }^{1}$, YeHui Zhang ${ }^{1}{ }^{*}$, Na Yang ${ }^{1}$, and Rui Wang ${ }^{2}$ \\ 'School of Hydrology and Water Resources, Nanjing University of Information Science and Technology, Nanjing 210044, China; \\ ${ }^{2}$ State Oceanic Administration Key Laboratory for Polar Science, Polar Research Institute of China, Shanghai 200136, China \\ Key Points: \\ - The diurnal cycle of the PBLH is apparent over land while the PBLH diurnal cycles are quite mild over oceans \\ - The median PBLH is positively correlated with the near-surface temperature and negatively correlated with the near-surface relative \\ humidity \\ - The daytime PBLH exhibits a statistically significant increasing trend at most latitudes
}

Citation: Gu, J., Zhang, Y. H., Yang, N., and Wang, R. (2020). Diurnal variability of the planetary boundary layer height estimated from radiosonde data. Earth Planet. Phys., 4(5), 479-492. http://doi.org/10.26464/epp2020042

\begin{abstract}
Diurnal variations in the planetary boundary layer height (PBLH) at different latitudes over different surface characteristics are described, based on 45 years (1973-2017) of radiosonde observations. The PBLH is determined from the radiosonde data by the bulk Richardson number (BRN) method and verified by the parcel method and the potential temperature gradient method. In general, the $B R N$ method is able to represent the height of the convective boundary layer (BL) and neutral residual layer cases but has relatively large uncertainty in the stable BL cases. The diurnal cycle of the PBLH over land is quite different from the cycle over ocean, as are their seasonal variations. For stations over land, the PBLH shows an apparent diurnal cycle, with a distinct maximum around 15:00 LT, and seasonal variation, with higher values in summer. Compared with the PBLH over land, over oceans the PBLH diurnal cycles are quite mild, the PBLHs are much lower, and the seasonal changes are less pronounced. The seasonal variations in the median PBLH diurnal cycle are positively correlated with the near-surface temperature and negatively correlated with the near-surface relative humidity. Finally, although at most latitudes the daytime PBLH exhibits, over these 45 years, a statistically significant increasing trend at most hours between 12:00 LT and 18:00 LT over both land and ocean, there is no significant trend over either land or ocean in the nighttime PBLH for almost all the studied latitudes.
\end{abstract}

Keywords: planetary boundary layer height; diurnal cycle; radiosonde

\section{Introduction}

The planetary boundary layer (PBL) is directly affected by the surface below the troposphere, and the magnitude is on the order of an hour or less (Stull, 1988). The PBL height (PBLH) is an important parameter in the study of the atmospheric boundary layer that may affect the distribution of aerosols, convective activities, and the formation of clouds and fog (Wulfmeyer et al., 2011; Li ZQ et al., 2017). Accurate estimation of the PBLH is important in the parameterization of the atmospheric model, in weather predicting promotion, and in climate and air quality monitoring (Guo JP et al., 2017; Liu L et al., 2018; Zhang YH and Li SY, 2019).

As observation technologies have advanced, many datasets have become available that can be used to assess the PBLH; among them are those from boundary layer radar, sonic detection and ranging (SODAR) (Clifford et al., 1994; Ao et al., 2012), cloud-aero-

Correspondence to: Y. H. Zhang, zhangyehui@nuist.edu.cn

Received 24 APR 2020; Accepted 09 MAY 2020.

Accepted article online 30 JUN 2020.

(C) 2020 by Earth and Planetary Physics. sol Lidar (Jordan et al., 2010; Su TN et al., 2017), radar wind profiler (Beyrich, 1997; Molod et al., 2015; Liu B et al., 2019) and some Global Positioning System radio occultation (GPS RO) measurements (Eresmaa et al., 2006; Chan and Wood, 2013). However, one of the most common sources of data for estimating the PBLH is long-term global radiosonde datasets (Seibert et al., 2000, Guo JP et al., 2019). Scholars often use the PBLH derived from radiosonde observations to evaluate results acquired from other datasets or from model simulations. Various methods and algorithms have been discussed in previous studies (Zhang WC et al., 2016). The parcel method is widely used in determining the convective boundary layer height, while the bulk Richardson (Ri) number method concept is usually used to obtain the stable boundary layer height. Seidel et al. (2012) discussed the uncertainties of the PBLH calculated by different methods and found that when large datasets are used, the bulk Richardson number method yields consistent estimates of the boundary layer height.

The PBLH exhibits significant diurnal variation. Its apparent diurnal cycle is typically controlled by solar radiation and cloud (Guo JP et al., 2016). The PBLH remains low at nighttime due to radiative 
cooling. The near surface layer tends to be stable, forming a stable boundary layer. However, the boundary layer deepens rapidly when the sun rises and daytime advances because of unstable convective conditions, causing a convective boundary layer. The upper part of the stable boundary layer is covered with the residual layer, which is not dissipated by the convective boundary layer during the daytime. The diurnal cycle of the PBLH has been discussed in many studies, but most of them have been based only on data from specific stations collected during relatively short time periods. For example, Norton and Hoidale (1976) first documented the PBLH diurnal cycle and seasonal variations by radiosonde data from 1961-1972 at one high-elevation station $\left(32.24^{\circ} \mathrm{N}, 106.22^{\circ} \mathrm{W}, 1216 \mathrm{~m}\right.$, mean sea level) over White Sands Missile Range, New Mexico. Liu SY and Liang XZ (2010) established a climatological diurnal cycle that grouped four different surface conditions (ice, land, oceans, and lakes) by using radiosonde data collected during 14 major field campaigns around the world. Ao et al. (2012) compared GPS RO data and data from the European Center for Medium-Range Weather Forecasts (ECMWF) Reanalysis Interim (ERA-Int) over the Sahara during summers to examine the PBLH distributions and annual and diurnal variability. Liu $Y$ et al. (2016) used GPS RO data to analyze diurnal variations in the top height of the atmospheric boundary layer in six different regions.

We have attempted to investigate the global PBLH diurnal cycle at different latitudes. We use the bulk Ri method to estimate the PBLH at different local times in each latitude zone, based on data derived from the Integrated Global Radiosonde Archive (IGRA) at the National Climatic Data Center (NCDC) and have verified the values by using the parcel and the potential temperature gradient methods. Section 2 presents the datasets and methods. Section 3 depicts characteristics of the PBLH, such as its quartiles and its seasonal and annual diurnal cycles. A summary follows in Section 4.

\section{Data and Methods}

\subsection{Radiosonde}

Variables in the IGRA (Durre et al., 2006; Durre and Yin XG, 2008) include pressure, temperature, geopotential height, and wind speed, etc. Climatological statistics are derived from twice-daily (00:00 and 12:00 UTC) sampling of the data over a 45-year period (1973-2017), since the data after 1973 are relatively of better quality (Wang XY and Wang KC, 2016). The mixing height is reported to have been less affected by data inhomogeneities after 1973 (Zhang YH et al., 2013).

It is difficult to derive the diurnal variation in the PBLH from these routine twice-daily radiosonde observations at each station. In this study, we have calculated the long-term annual/median PBLHs at 00:00 and 12:00 UTC at each station. Accordingly, these two observational times could be converted to different local times that could be used to reveal a daily variation in the PBLH around a latitude circle. For the analysis of diurnal variations in the PBLH at different latitudes, we selected a representative climate zone in each of the low, middle, and high latitudes to guarantee a consistent climate factor. In the low latitudes, our choice was the Tropical Desert Climate zone from $20^{\circ} \mathrm{N}-30^{\circ} \mathrm{N}$ over the Northern
Hemisphere low latitudes (NL) and $20^{\circ} \mathrm{S}-30^{\circ} \mathrm{S}$ over the Southern Hemisphere low latitudes (SL) (Daher et al., 2018). In the middle latitudes, we chose the Mediterranean Climate zone from $30^{\circ} \mathrm{N}-40^{\circ} \mathrm{N}$ over the Northern Hemisphere middle latitudes (NM) and from $30^{\circ} \mathrm{S}-40^{\circ} \mathrm{S}$ over the Southern Hemisphere middle latitudes (SM) (Cherfouh et al., 2018). In the high latitudes, the climate zones in the Northern and Southern Hemispheres are not similar. We chose the Coniferous Climate zone $\left(60^{\circ} \mathrm{N}-70^{\circ} \mathrm{N}\right)$ in the Northern Hemisphere high latitudes $(\mathrm{NH})$ and southern Frigid Climate zone $\left(60^{\circ} \mathrm{S}-70^{\circ} \mathrm{S}\right)$ in the Southern Hemisphere high latitudes (SH) (Tang XG et al., 2017). Moreover, the environmental and physical changes in the equatorial region have received widespread attention (Pavlov and Pavlova, 2007). Therefore, the equatorial areas are also included in this study. We chose the Tropical Rainforest Climate zone from $0^{\circ} \mathrm{N}-10^{\circ} \mathrm{N}$ over the northern equator (EN) and $0^{\circ} \mathrm{S}-10^{\circ} \mathrm{S}$ over the southern equator (ES) (Bissinger and Bogner, 2018). For every latitude zone selected, observational data were available to cover effectively all 24 hours of local time.

The latitude zone with the largest number of stations (221) is the Northern Hemisphere middle latitudes; the latitude zone with the smallest number of stations (11) is the Southern Hemisphere high latitudes. For all the latitude bins, the available soundings number more than $10^{5}$. All these stations are grouped into two categories by major surface characteristics: land and ocean. It is noteworthy that coastal stations and several stations located on islands are grouped into the ocean category, due to their similar PBLH features. The detailed numbers of these two categories, along with the station locations, are shown in Figure 1. For the three Northern latitude regions, the number of stations in the land category is larger than in the ocean category. However, in the equatorial areas and in the Southern Hemisphere, more stations are in the ocean category than in the land category. In addition, we would like to emphasize that interpretation of the results in the Southern Hemisphere high latitudes (SH) should be taken with caution, since there are only eleven stations in regions characterized by ice, and thus many fewer soundings are available in this latitude bin than in those of the other regions.

\subsection{Planetary Boundary Layer Height Estimates}

To determine the PBLH, the bulk Richardson number (BRN) method revised by Vogelezang and Holtslag (1996) is used. The BRN method is not strongly dependent on the vertical resolution and it can identify a nonnegative height in all cases (Zhang YH et al., 2013). The formula of the bulk $R i$ is defined as:

$$
\operatorname{Ri}(z)=\frac{\left(\frac{g}{\theta_{v s}}\right)\left(\theta_{v z}-\theta_{v s}\right)\left(z-z_{s}\right)}{\left(u_{z}-u_{s}\right)^{2}+\left(v_{z}-v_{s}\right)^{2}+\left(b u_{*}^{2}\right)^{\prime}}
$$

where $g$ is gravity acceleration, $\theta_{v}$ is the virtual potential temperature, $z$ is the calculated potential height, $u$ and $v$ are zonal and meridional wind speeds, respectively, $b$ is a constant whose reasonable estimation is on the order of 100 (Vogelezang and Holtslag, 1996), and $u_{*}$ is the surface friction velocity. The subscript $s$ represents the surface, and $z$ is the altitude of the calculated layer. The friction velocity $u_{*}$ in the denominator is much smaller than wind shear items, so we ignore surface friction terms. Because winds at the surface $(2 \mathrm{~m}$ level) are not included in radio- 

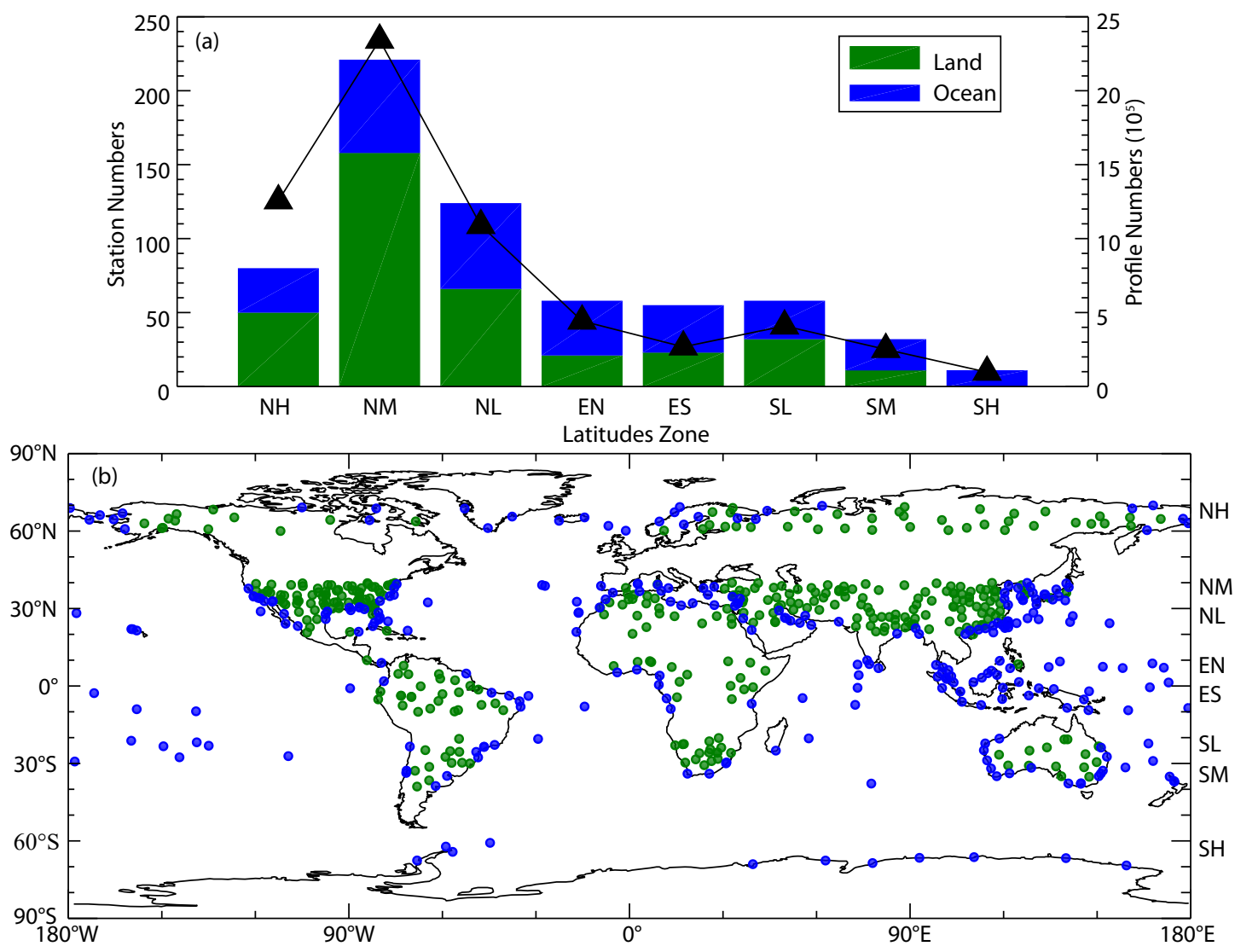

Figure 1. (a) Stations and sounding numbers of eight latitude zones. Color column and black triangles represent stations and sounding numbers, respectively. Green column denotes number of land stations; blue column denotes number of ocean stations. (b) Site map in different regions. $\mathrm{NH}, \mathrm{NM}, \mathrm{NL}, \mathrm{EN}, \mathrm{ES}, \mathrm{SL}, \mathrm{SM}$, and $\mathrm{SH}$ in the horizonal axis mean high latitude $(\mathrm{H})$, middle latitude $(\mathrm{M})$, low latitude $(\mathrm{L})$, equator $(\mathrm{E})$ in the Northern Hemisphere $(\mathrm{N})$ and Southern Hemisphere $(\mathrm{S})$.

sonde reports, in our calculations we take the wind speed to be 0 $\mathrm{m} / \mathrm{s}$ at the first level in the wind measurements. The results were similar. In this article, the winds were set to zero for consistency with other radiosonde data research (Vogelezang and Holtslag, 1996; Seidel et al., 2012).

Soundings with more than 4 levels of wind speed records and 7 levels of records with a temperature below $5 \mathrm{~km}$ have been selected. Sensitivity analyses in Zhang YH et al. (2013) have shown that changing these requirements does not substantially influence the data retention rate. This method determines the height at which bulk $R i$ reaches a value of 0.25 .

To verify the results derived from the BRN method, we also use the parcel method and the potential temperature gradient method to estimate the PBLH. The parcel method can determine a mixing height by comparing the virtual potential temperature at the surface to values aloft and evaluating the height at which the virtual potential temperature is the same as at the surface. The method proposed by Liu SY and Liang XZ (2010) uses the potential temperature profile to divide the boundary layer into three regimes: convective boundary layer $(\mathrm{CBL})$, stable boundary layer $(\mathrm{SBL})$, and neutral residual layer (NRL). The type of boundary layer can be distinguished by calculating the difference in potential temperature between $200 \mathrm{~m}$ and $50 \mathrm{~m}$. The specific calculation formula can be found in Liu SY and Liang XZ (2010). We interpol- ate the data to a vertical resolution of $50 \mathrm{~m}$ to obtain the potential temperature at $200 \mathrm{~m}$ and $50 \mathrm{~m}$.

Figure 2 gives an example of the vertical profiles in the virtual potential temperature (a), wind speed (b), and $R i(z)(c)$ based on the 12:00 UTC 19 June 2017 radiosonde observation at KABUL AIRPORT $\left(34.55^{\circ} \mathrm{N}, 69.2167^{\circ} \mathrm{E}, 1791 \mathrm{~m}\right)$. Figure 2a identifies a layer at $3517 \mathrm{~m}$ by the parcel method; Figure $2 \mathrm{c}$ determines a layer at $3569 \mathrm{~m}$ through $R i(z)$. The two methods show similar results. To further compare results of these two methods, we calculate related coefficients of the parcel method and the BRN method at station OSAN $A B\left(37.08^{\circ} \mathrm{N}, 127.03^{\circ} \mathrm{E}, 11.8 \mathrm{~m}\right)$; their results are highly consistent; their correlation is 0.9 . Similar results are also shown in data from most other stations. According to results by comparison, the result of the bulk $R i$ method $z(R i=0.25)$ is considered to identify the mixing height. Furthermore, we also compared the results using the method proposed by Liu SY and Liang $X Z$ (2010) with the BRN method $z(R i=0.25)$. The results show that correlations at the CBL (near 0.8) and NRL (near 0.7) are relatively high, but not at the SBL. This difference is not surprising because the SBL observations are mostly at quite low heights. According to the uncertainty test in Seidel et al. (2012), the uncertainties in the BRN method can be large ( $>50 \%)$ for the low $z(R i=0.25)$. In summary, according to our analysis, the BRN method could satisfactorily represent the height in the CBL and NRL cases, but can be ex- 

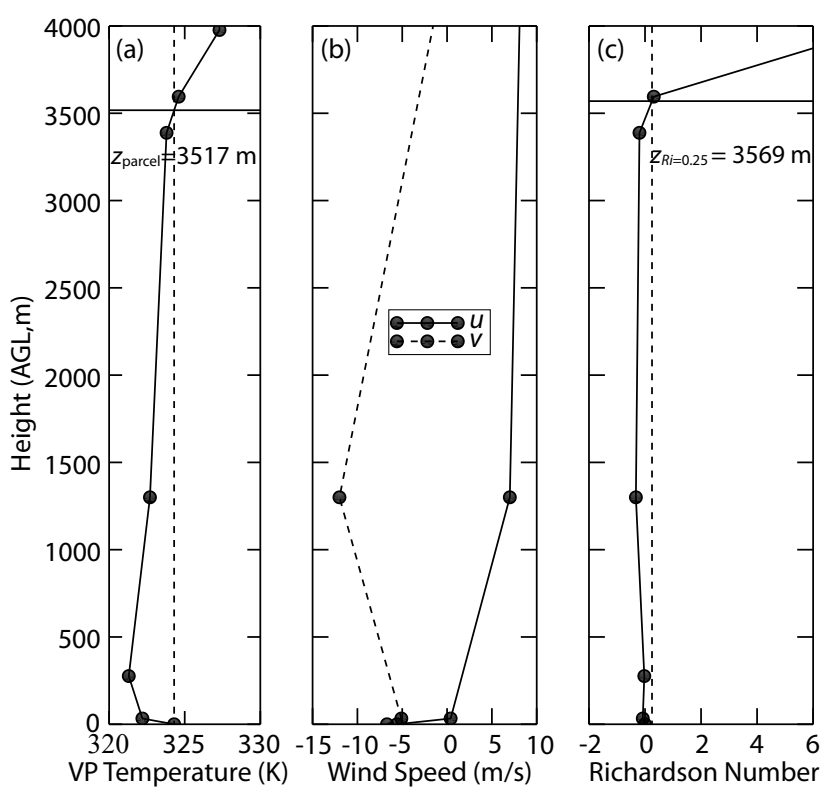

Figure 2. Vertical profiles of virtual potential temperature (a), wind speed (b), and $\operatorname{Ri}(\mathrm{z}$ ) (c) based on the 12:00 UTC 19 June 2017 radiosonde observations at KABUL AIRPORT $\left(34.55^{\circ} \mathrm{N}, 69.22^{\circ} \mathrm{E}\right.$, $1791 \mathrm{~m}$ ) from the IGRA. Black dots are the observed data records and $u$ and $v$ represent zonal and meridional winds, respectively. pected to have a relatively large uncertainty in the SBL cases. In order to use a consistent method in the large radiosonde data set, hence, $\mathrm{BRN} z(R i=0.25)$ is the main PBLH metric used in this climatological study.

According to the classification standard of the potential temperature gradient method, we make a frequency analysis of three boundary regimes at the two surface characteristics shown in Figures. 3 and 4. Over land (Figure 3), the stable (SBL) regimes are observed to appear with frequency of about $40 \%$ at night but rarely exist in the daytime; a contrary pattern characterizes the unstable (CBL) regimes; the NRL frequency is about $90 \%$ in the daytime and greater than $60 \%$ over the 24 -hour day. Over ocean (Figure 4), the CBL appears more frequently in the daytime from 09:00 to 18:00 LT compared to land, and the NRL is seen with less frequency $(\sim 40-80 \%)$ than over above land. The different results between land and ocean may reflect the much stronger diurnal variations of surface temperature over land than ocean (Liu SY and Liang XZ, 2010).

\subsection{Trend Analysis}

Trends were computed for median PBLH at 24 hours of the day during the periods of 1973-2017. The non-parametric median of pairwise slopes method (Lanzante, 1996), with statistical significance levels based on Spearman rank-order tests, was used to es-
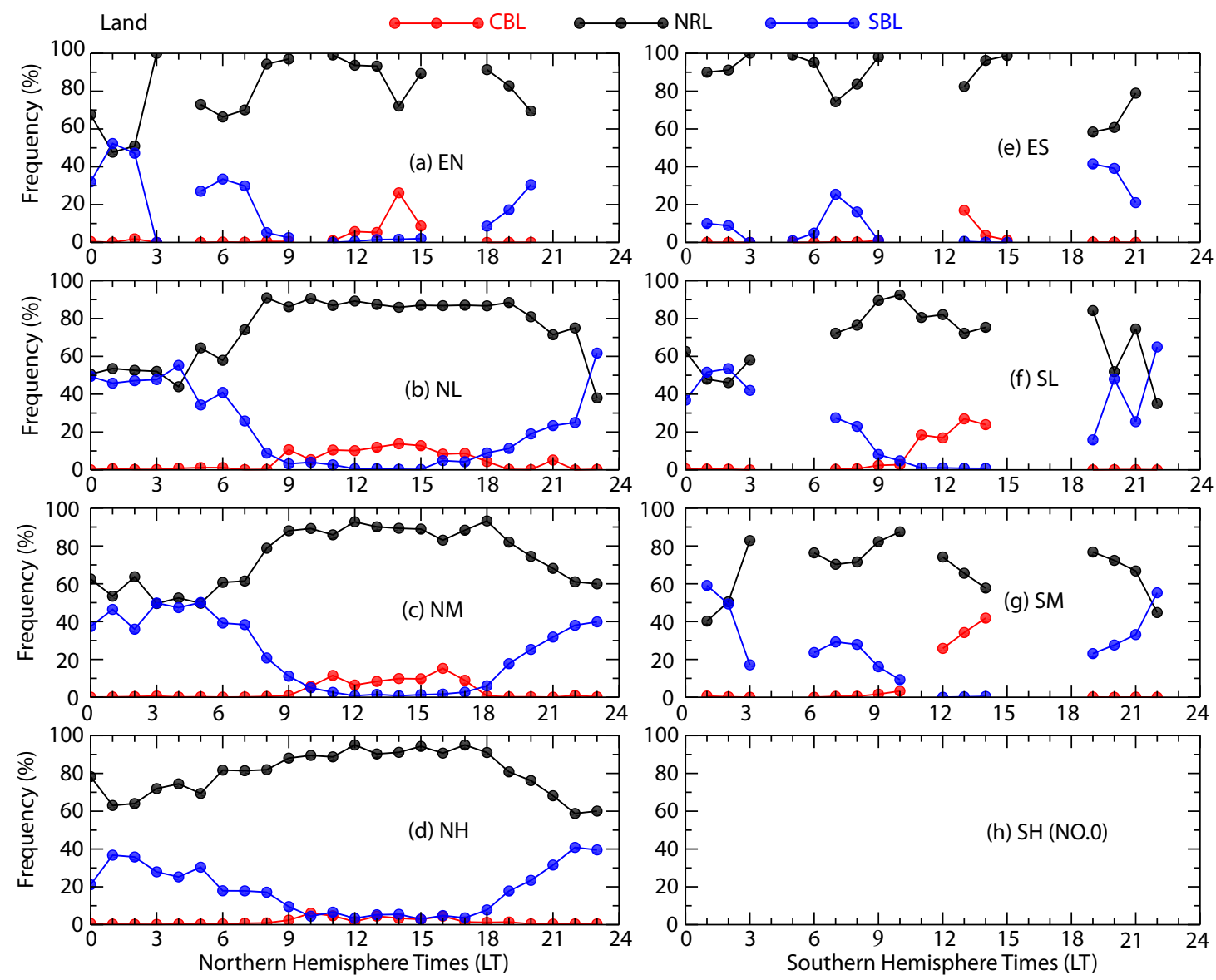

Figure 3. The frequency distributions of CBL (red), NRL (black), and SBL (blue) across the diurnal cycles in different latitudes over land in the Northern (a (EN), b (NL), c (NM), d (NH)) and Southern (e (ES), f (SL), g (SM), h (SH)) Hemispheres. Time has been converted to local time in 1-h intervals. 

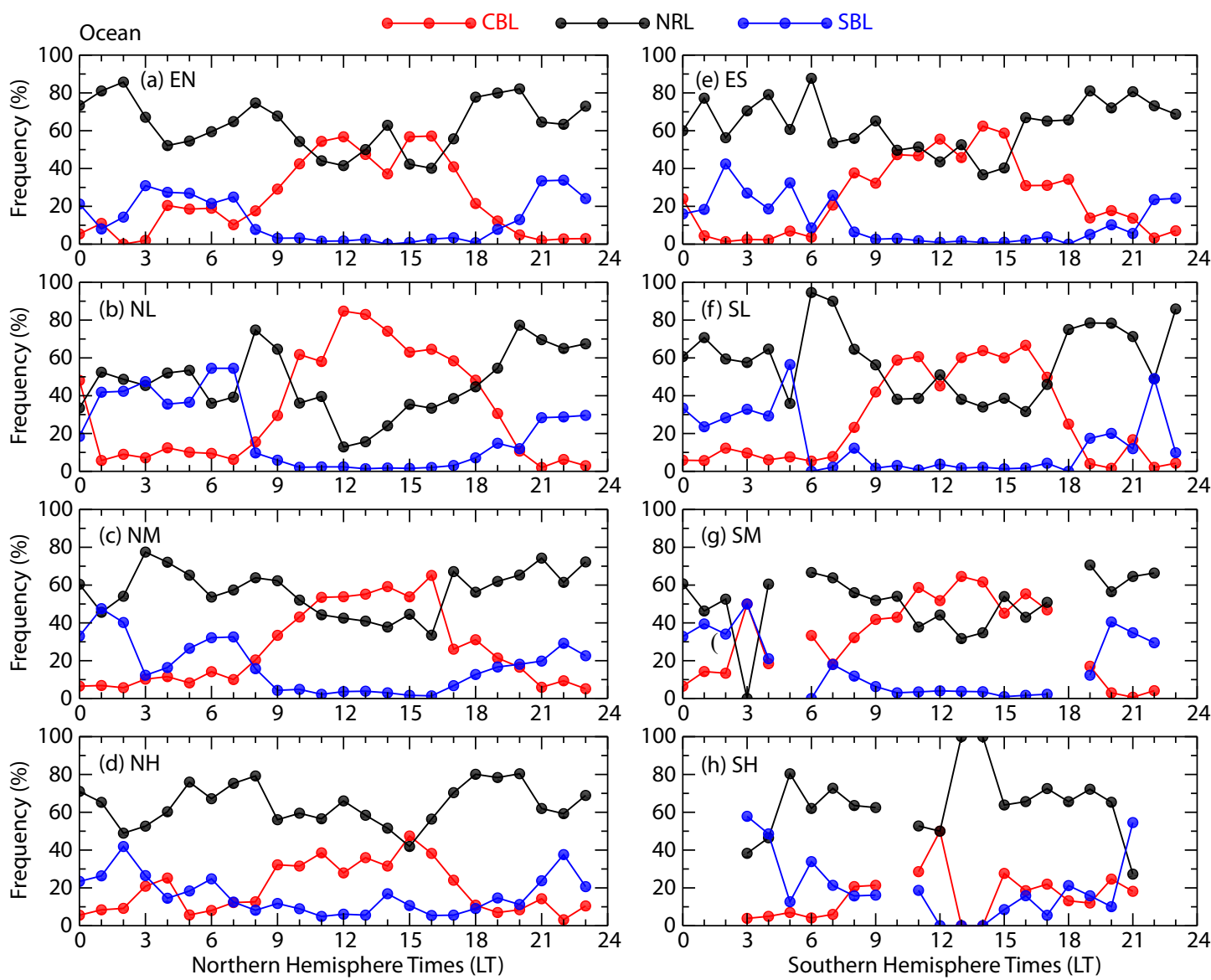

Figure 4. Similar to Figure 3, but for stations over oceans.

timate the trends. The procedure is computed as:

$$
b_{k}=\left(y_{i}-y_{j}\right) /\left(x_{i}-x_{j}\right),
$$

here $b_{k}$ is the slope between a pair of points $\left(x_{j}, y_{j}\right)$ and $\left(x_{i}, y_{i}\right)$. If $N$ is the total number of points, then the pairwise slopes will be $N(N-1) / 2$; the final calculation of $b$ is regarded as the median of the $b_{k}$ values. This estimated slope is then used to compute the residuals for all $N$ points:

$$
\text { res }_{k}=y_{i}-\left(b x_{i}\right)
$$

The intercept ' $a$ ' is estimated as the median of these residuals and the regression equation is:

$$
\hat{y}_{i}=a+\left(b x_{i}\right) .
$$

Station data were considered sufficient if at least 50 soundings per season were available for identifying the PBLH in a given year and at least 30-years of such data were available during the study period (45 years).

\section{Results}

\subsection{Four Measures of the Diurnal Cycle}

Due to solar radiation and surface radiation, the diurnal variation in the PBLH displays obvious changes. However, these diurnal variations in the PBLH can be different from region to region. Since most IGRA stations provide only twice-daily observations, it is difficult to directly obtain the diurnal variations of the PBLH at each site. But the local observing times of these IGRA stations are basically enough to cover 24 hours in one day. When converting UTC to local time (LT), there are sufficient observations in each latitude zone to study the diurnal variations in the PBLH. We studied the PBLH diurnal cycle in different latitudes over two different surface characteristics (land and ocean), separately.

Figures 5 and 6 present the diurnal cycles of the PBLH in different latitudes among the Northern $(a, b, c, d)$ and Southern $(e, f, g, h)$ Hemispheres over land and oceans, respectively. The values we chose to examine are indicated as follows: the $25^{\text {th }}$ percentile (green dashed line), $50^{\text {th }}$ (median) percentile (red solid line), and $75^{\text {th }}$ percentile (green dash-dotted), along with the mean value (blue solid line) of the PBLH. Since most stations are coastal or on islands in the equatorial region and in the Southern Hemisphere, the diurnal cycles of the PBLH in these regions present only the results at some hours with the available qualified soundings. In addition, the diurnal cycles of the PBLH in different latitudes, based on the potential temperature gradient method (not shown) proposed by Liu SY and Liang XZ (2010), reveal a pattern similar to that of Figures 5 and 6.

Generally, the diurnal cycles of the PBLH over land and over oceans are quite different. For stations over land, the PBLH shows an apparent diurnal cycle, with a distinct maximum around 15:00 LT. Basically, in all studied latitudes, the nighttime PBLHs from 19:00 to 07:00 LT are usually stable, and most are lower than $500 \mathrm{~m}$. The differences between the $75 \%$ and $25 \%$ quartiles are quite 

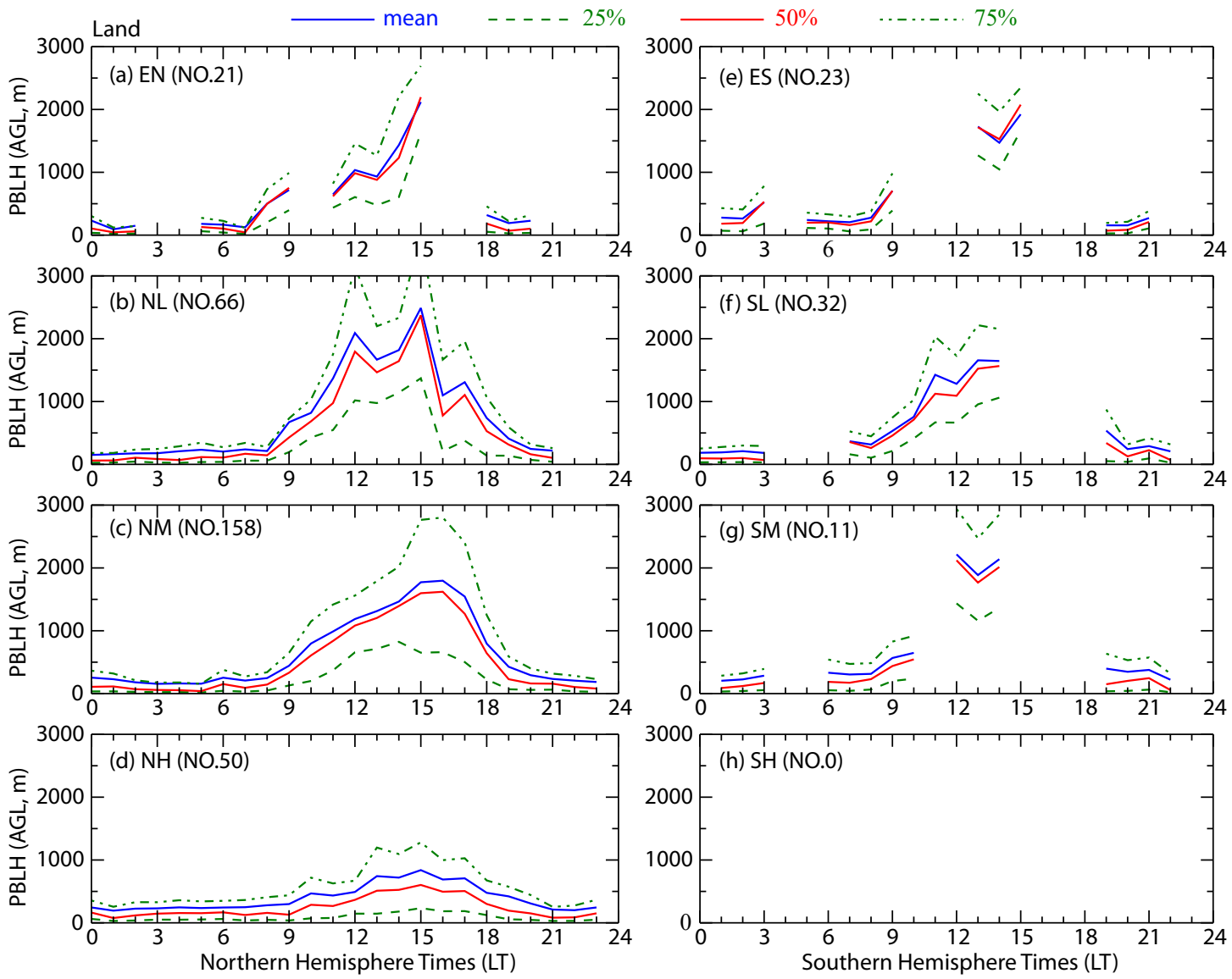

Figure 5. The PBLH diurnal cycles in different latitudes over land in the Northern $(a, b, c, d)$ and Southern (e, $f, g, h)$ Hemispheres. Shown are the $25^{\text {th }}, 50^{\text {th }}$, and $75^{\text {th }}$ percentiles of the PBLH along with its average, based on all records (UTC converted to LT) that fall within corresponding latitudes in 1-h intervals.

small, indicating small fluctuations at night. Except for the high latitudes, the PBLH rises slowly from 07:00 to 15:00 LT and falls relatively steeply from 15:00 to 19:00 LT (17:00 to 19:00 LT for NM region), with values generally higher than $1000 \mathrm{~m}$ around noon. Compared to the nighttime PBLH, the magnitude of daytime $\mathrm{PBLH}$ variations is much larger, especially in the Northern low and middle latitudes. From 12:00 to 17:00 LT, the differences between the $75 \%$ and $25 \%$ quartiles in these two regions (Figures $5 b, 5 c$ ) are quite large. These findings agree well with previous results reported in Chu YQ et al. (2019) and Liu SY and Liang XZ (2010).

According to Figure 5, the maximum PBLH decreases from low latitude areas to high latitude areas. Generally, the thermal radiation decreases toward the polar region, which results in a relatively low PBLH in the high latitudes. Over land, the median PBLH reaches its maximum at approximately 15:00 LT for most latitudes in the Northern Hemisphere, in agreement with Liu SY and Liang $X Z$, (2010) which also report peak PBLH at around 15:00 LT. Zhang $\mathrm{YH}$ et al. (2014) also found that the maximum PBLH occurred in the afternoon, usually at 16:00 LT (no 15:00 LT observations available) over Yichang, China $\left(30.7^{\circ} \mathrm{N}, 111.3^{\circ} \mathrm{E}\right)$, which use 3-hour interval data (from 01:00 LT to 22:00 LT). The PBLHs in the high latitudes $(\mathrm{NH})$ stay stable below $1000 \mathrm{~m}$, although slight diurnal variations can be observed. It is noteworthy that the diurnal variations of the PBLH in the NL region show a bimodal structure, with PBLH peaks at 12:00 LT and 15:00 LT.

As compared with land, the PBLH diurnal cycles over oceans are quite mild (Figure 6) and the PBLHs are much lower. In general, the nighttime PBLHs over oceans from 20:00 to 08:00 LT are stable, and most of their heights are greater than those over land. The differences between the $75 \%$ and $25 \%$ percentiles are quite small. In the ES, EN, NL and NM regions, the PBLH over oceans rises slowly from 08:00 to around 14:00 LT and falls slowly from 15:00 to 20:00 LT, with peaks around $1000 \mathrm{~m}$. In the daytime, no obvious peak is shown in the PBLHs in the SL region, with a constant high mean value $(1000 \mathrm{~m})$ presented for a longer time (from 10:00 LT to 17:00 LT).

In the equatorial area, the nighttime PBLHs over oceans seem slightly higher than those in the other latitude bins. However, the daytime equatorial PBLHs, especially at noon, are lower than those in the low and middle latitudes. This finding agrees well with the results of Ao et al. (2012), who found that the PBLH in the equatorial area from $-5^{\circ} \mathrm{S}$ to $35^{\circ} \mathrm{N}$, derived from ECMWF reanalysis datasets, was lower than that in the low latitudes. In general, the Tropical Rainforest Climate has high temperatures and much rainfall throughout the year (Bissinger and Bogner, 2018); the latitude zones (EN and ES) we selected are in this climate type. In this region, temperature differences are small throughout the year. High temperatures may indicate a higher PBLH at night. During the 

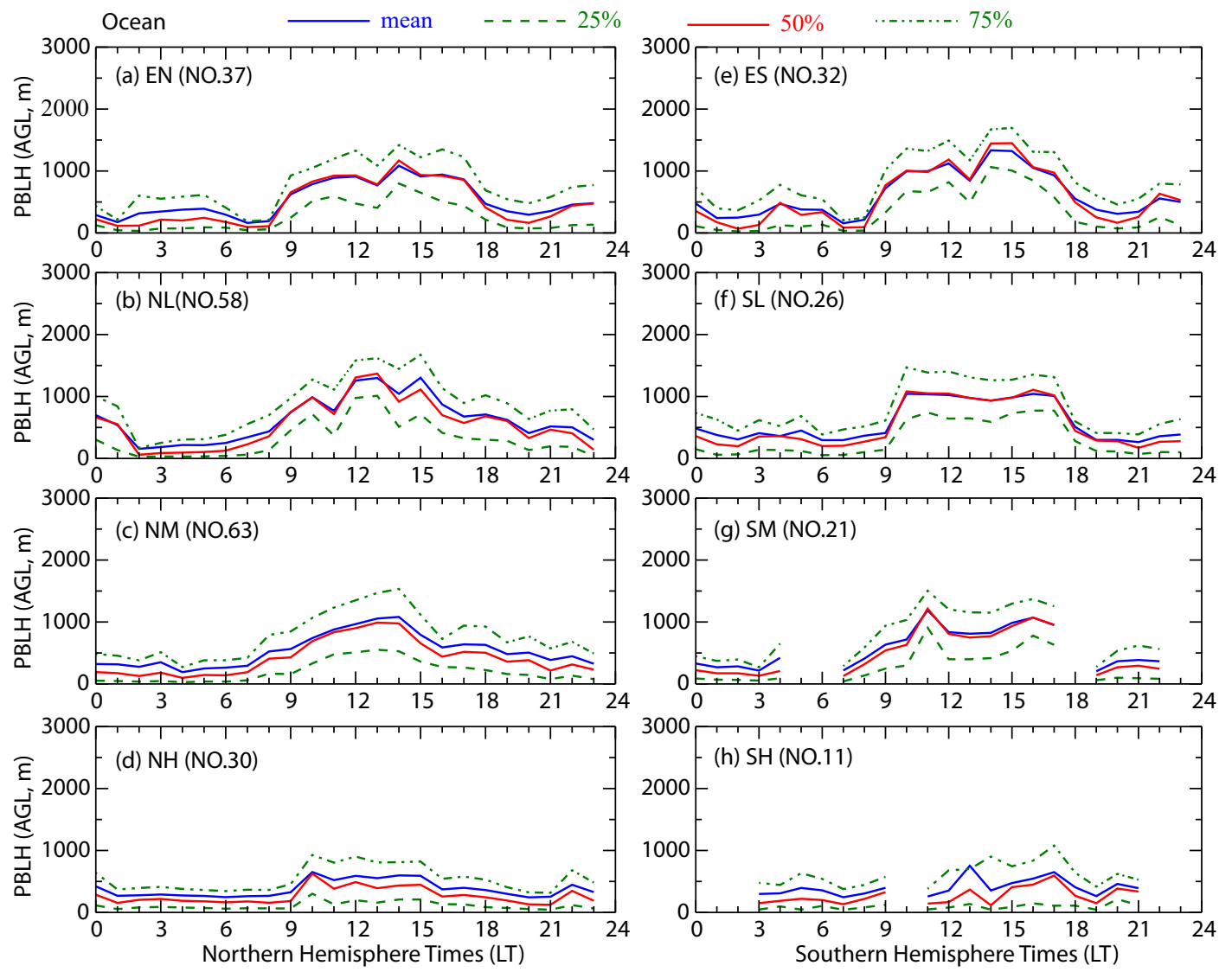

Figure 6. Similar to Figure 5, but for stations over oceans.

daytime, air convection easily occurs with high temperatures and humidity, and rain tends to occur. The larger humidity may make the PBLH in the equatorial region lower. This finding is consistent with the result in Zhang YH et al. (2013), who found in Europe a positive correlation between the PBLH and near-surface temperature and a negative correlation between the PBLH and near-surface relative humidity. In addition, the different albedo levels of the clouds may also change the PBLH (Liu Y et al., 2016).

Figures 5 and 6 also show that the mean value of the PBLH is similar to the median ( $50^{\text {th }}$ percentile) result both over land and ocean, which is consistent with the results reported by Liu SY and Liang XZ (2010). They studied the PBLH diurnal cycle at 14 different sites and also found that the average and median values are close to each other. However, the land-ocean contrast is obvious in the diurnal cycle of the PBLHs. For example, in the NL region, the diurnal variation in the PBLHs over land shows two peaks with time at 12:00 LT and 15:00 LT, while the one over oceans peaks at around 13:00 LT. Even if the soundings we choose come from the same climate type, there are still some differences between different surface characteristics (e.g., EN and ES). Besides, the differences between the $75 \%$ and $25 \%$ percentiles over land are small at night and increase from 10:00 to 15:00 LT, but these differences over oceans are quite consistent at most observing times.

\subsection{Seasonal Diurnal Variations}

Figure 7 shows the median diurnal PBLH cycle for different latitudes over land in the four seasons. In general, for both hemi- spheres (except for the equatorial areas) the daytime PBLH over land shows an apparent seasonal cycle: the highest daytime land PBLHs occur mainly in summer (JJA in the Northern Hemisphere and DJF in the Southern Hemisphere), and the lowest PBLHs usually occur in winter (DJF in the Northern Hemisphere and JJA in the Southern Hemisphere). The land PBLH in spring is slightly higher than that in autumn. This result is consistent with the findings from the study by Liu SY and Liang XZ (2010) over Atmospheric Radiation Measurement Program's Southern Great Plains (ARM SGP) $\left(36^{\circ} \mathrm{N}, 97^{\circ} \mathrm{W}, 315 \mathrm{~m}\right)$. The PBLH differences among the four seasons in the EN and ES regions are small, which may be because solar radiation is not much different during the four seasons in these regions. The nighttime PBLH exhibits little seasonal variation; the values are quite close to each other among the four seasons in all studied regions.

Compared to the results over land, the PBLHs over oceans (Figure 8) show less seasonal variation either in the daytime or at night in both hemispheres and the differences among the four seasons are relatively small for most studied regions, except for the high latitudes. The daytime PBLHs in the $\mathrm{NH}$ and $\mathrm{SH}$ regions (10:00 to 18:00 LT) present a clear seasonal cycle, with maximum in summer and minimum in winter.

To interpret the seasonal variations in the PBLH diurnal cycle, we calculated the near-surface $(2 \mathrm{~m})$ temperature $\left(T_{\text {sfc }}\right)$ and surface relative humidity $(R H)$ diurnal cycle in the four 4 seasons for different latitudes over both land and ocean surface characteristics. Atmospheric water vapor may have a positive feedback on surface 


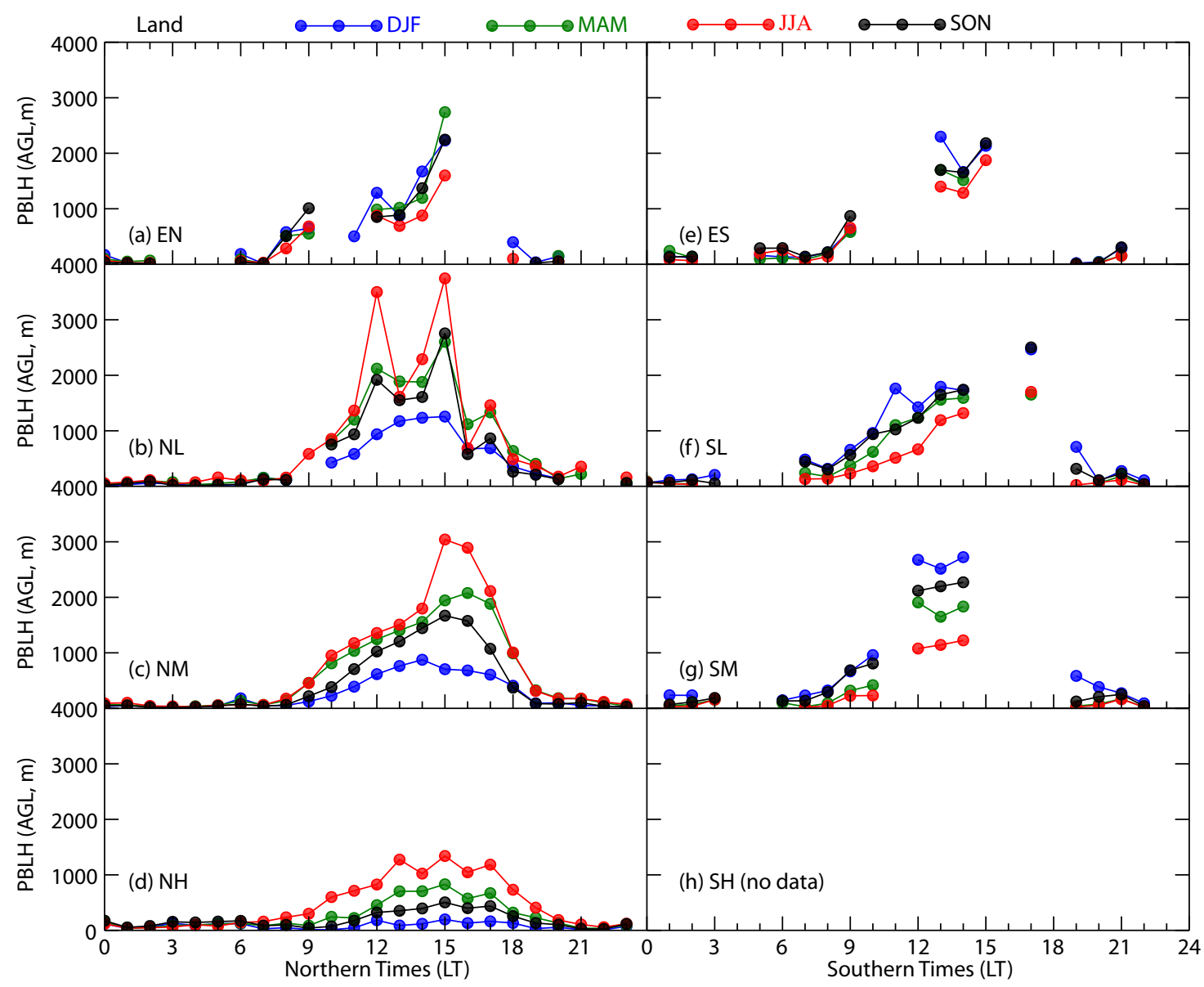

Figure 7. The median PBLH diurnal cycle over land in the four seasons for different latitudes in the Northern (a, b, c, d) and Southern (e, $f, g, h)$ Hemispheres. DJF means December, January, and February. MAM means March, April, and May. JJA means June, July and August. SON means September, October and November.

temperature since it is considered to be a greenhouse gas (Raval and Ramanathan, 1989). Zhang YH et al. (2013) reported that a higher surface temperature and a lower $R H$ results in greater sensible heat flux and lower latent heat flux, which can lead to deeper convection and a higher PBLH. Recent research has indicated that different soil moisture heterogeneities over land may also affect the seasonal and regional PBLH (Guo JP et al., 2019).

Figure 9 presents the diurnal cycle of the averaged near-surface relative humidity $(R H)$ and near-surface temperature $\left(T_{\text {sfc }}\right)$ over oceans and land in the middle latitudes of the Northern Hemisphere. For those stations over oceans, the near-surface $R H$ shows little seasonal cyclicality; the values in all four seasons are close to each other all day, while the near-surface temperature shows clear seasonal variation but the $T_{\text {sfc }}$ differences remain small and consistent in all four seasons. The results in the NM region over oceans are similar with PBLHs in the four seasons at most observing times (Figure $8 \mathrm{c}$ ). Results over oceans in the other regions are similar; the $T_{\text {sfc }}$ differences remain small and consistent throughout the whole year, and the $R H$ shows less seasonal variation compared to that over land (not shown). This may be because the ocean has a large thermal capacity and may explain to some extent the fact that the PBLH over oceans shows less seasonal variations than that over land. Moreover, the inclusion of data from many coastal stations, which present a mixture of ocean and land conditions, may also have some impact on the results.

As compared with ocean, the $R H$ and $T_{\text {sfc }}$ diurnal cycles over land in the NM region are quite apparent (Figure $9 \mathrm{c}$ and $9 \mathrm{~d}$ ). The $T_{\mathrm{sfc}}$ is highest in summer and lowest in winter throughout the whole day and the values in spring and autumn are close to each other. The $R H$ shows a complicated seasonal variation in one day. For examples, at 02:00-05:00 LT and 10:00-17:00 LT, the maximum is in winter and minimum is in summer. On the contrary, at 06:00-09:00 LT and 18:00-21:00 LT, the $R H$ peaks in summer and has its lowest value in winter/spring. The seasonal cycle in the PBLH over land in the NM region (Figure 7c) suggests that the PBLH is positively correlated with the $T_{\text {sfc }}$ and negatively correlated with the near-surface $R H$ in the daytime (10:00-18:00 LT). For example, the peak PBLH value at 15:00 LT in the NM region (Figure 7c) corresponds to the time of the lowest value of $R H$ (Figure $9 c)$. Besides, over land in the NL region (not shown), the $R H$ is consistently lowest at 12:00 and 15:00 LT in summer, spring, and autumn, but only one lowest value at 12:00 LT was observed in winter. The minimums of $R H$ seem correlated with the maximums of the PBLH in this region (Figure $7 \mathrm{~b}$ ). This suggests that the bimodal structure in its PBLH variation over land may have some association with the changes in near-surface $R H$. 


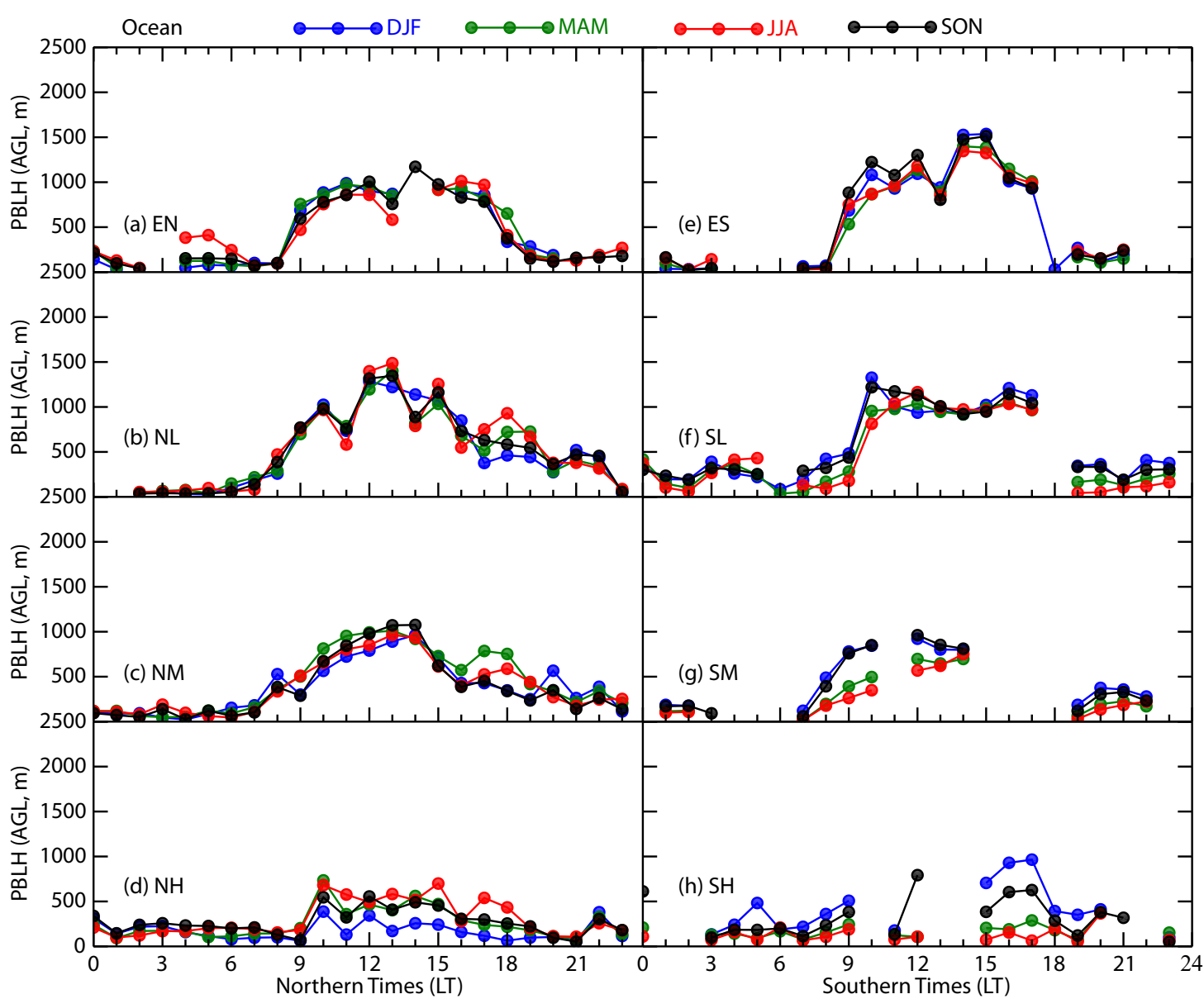

Figure 8. Same as Figure 7, but for stations over oceans.

The $T_{\text {sfc }}$ and $R H$ differences in the equatorial regions over oceans are quite small throughout the whole year (not shown), which may indicate small differences in the PBLHs in these regions (Figure $8 \mathrm{a}$ and $8 \mathrm{e}$ ). Although the $T_{\mathrm{sfc}}$ differences in the equatorial regions over land are also small, the $R H$ in the EN region shows an obvious seasonal variation, especially from 11:00 to 15:00 LT, with maximum in summer and minimum in winter. As shown in Figure $7 \mathrm{a}$, the PBLH over land in the EN region presents higher values in winter and lower values in summer from 11:00 to 15:00 LT. The negative correlation between the PBLH and $R H$ is also confirmed in the equatorial area.

Therefore, we calculated correlation coefficients between the PBLH and these two physical parameters (Table 1 and Table 2) based on the diurnal cycle in the four seasons for different latitudes over land and ocean; the numbers in bold indicate correlations that are significant at the $95 \%$ or greater confidence level. For almost the whole region (except the $\mathrm{SH}$ region due to no available data) over land, the PBLH shows two coincidently statistically significant correlations in all seasons: a positive correlation with the near-surface temperature and a negative correlation with the $R H$. This finding is consistent with the results of PBLH studies over the US and Europe by Seidel et al. (2012) and Zhang YH et al. (2013). These correlations suggest that, for most of these regions, on a daily scale, a lower near-surface $R H$ and higher $T_{\text {sfc }}$ will signal a higher PBLH. However, it is noteworthy that for most coastal stations or stations on islands, more complicated physical processes will influence the PBLH, such as sea fog (Zhang YH and Li SY, 2019). Liu $Y$ et al. (2016) also noted that different cloud types have different albedos and will influence the marine boundary layer height (MBLH).

\subsection{Trends in the PBLH at Each Hour}

Figures 10 and 11 show long-term trends from 1973 to 2017 in the median PBLHs at each of the 24 hours, over land and oceans, respectively. A solid circle indicates that trends are significant at the $95 \%$ or greater confidence level. A value greater than 0 indicates an increasing trend, and a value less than 0 indicates a decreasing trend. PBLH trends were determined using data from only those stations for which a minimum of 30 years of data were available at the given hour. Therefore, only in the $\mathrm{NM}$ and $\mathrm{NH}$ regions over land are trends available for most hours of the day; the stations over oceans in the Northern Hemisphere provided sufficient data to obtain trends over the full 24-hour day.

In general, there was no significant trend in the nighttime PBLH for almost all the studied latitudes over both land and ocean surfaces, which is consistent with the nighttime trends over Europe reported by Zhang YH et al. (2013). For stations in the NM and $\mathrm{NH}$ regions over land, however, the daytime PBLH exhibits a statistically significant increasing trend over these years at most hours between 12:00 LT and 18:00 LT. The largest increasing trend in the daytime PBLH occurs at 15:00 LT in the NM region, at a rate of 34.7 

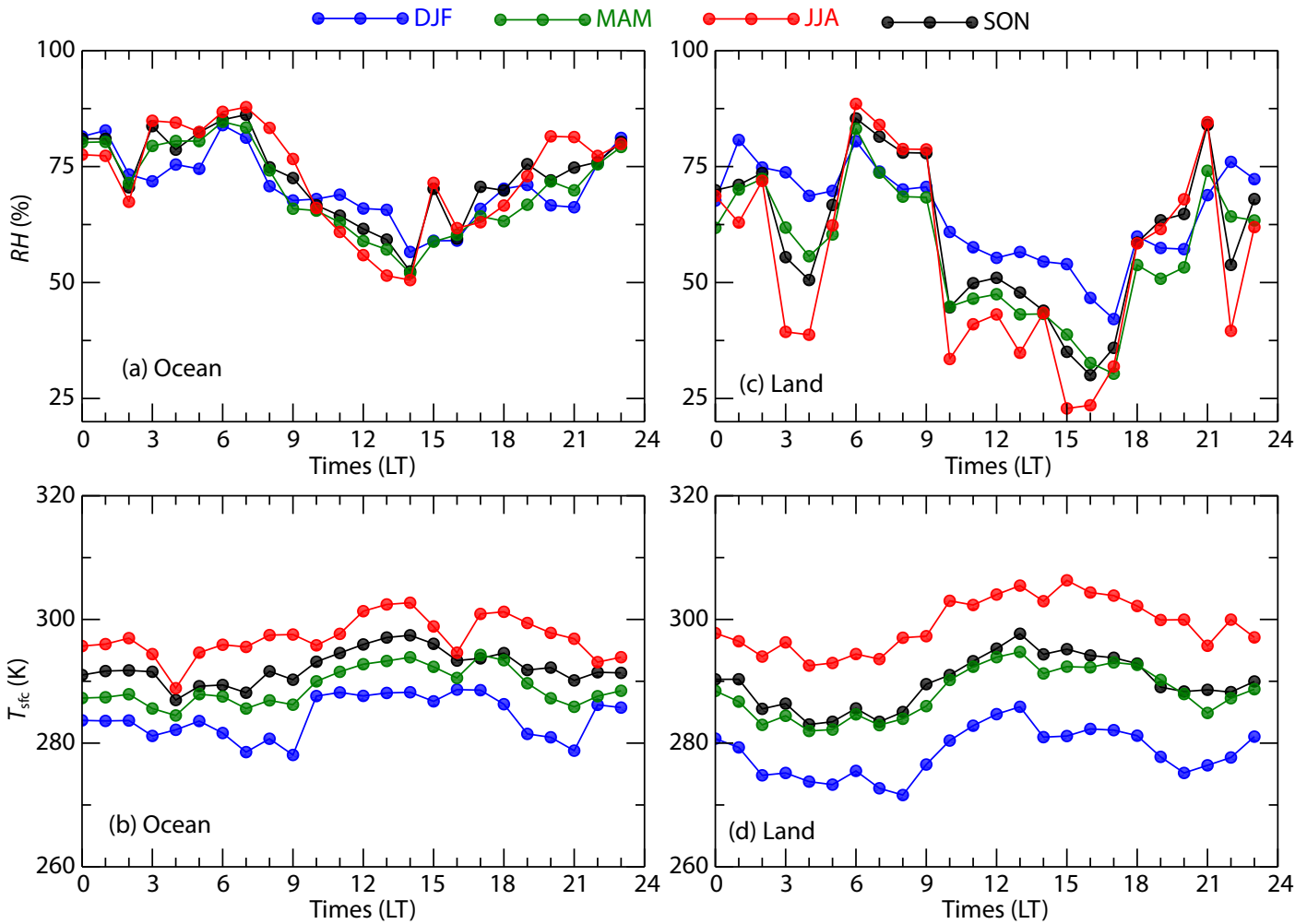

Figure 9. The diurnal cycle of the averaged near-surface relative humidity $(R H)$ (the upper row) and near-surface temperature $\left(T_{\text {sfc }}\right)$ (the lower row) over oceans (the right panel) and land (the left panel) in the middle latitudes of the Northern Hemisphere (NM).

Table 1. Correlation coefficients between the PBLH and two physical parameters (surface temperature and surface relative humidity) over land. Bold figures are significant at the $95 \%$ confidence level or greater.

\begin{tabular}{|c|c|c|c|c|c|c|c|c|}
\hline Latitude Zone (Land) & \multicolumn{2}{|c|}{ December-February (DJF) } & \multicolumn{2}{|c|}{ March-May (MAM) } & \multicolumn{2}{|c|}{ June-August (JJA) } & \multicolumn{2}{|c|}{ September-November (SON) } \\
\hline EN & -0.64 & 0.60 & -0.78 & 0.42 & -0.88 & 0.29 & -0.92 & 0.54 \\
\hline NL & -0.39 & 0.81 & -0.42 & 0.75 & -0.38 & 0.83 & -0.48 & 0.82 \\
\hline NM & -0.71 & 0.66 & -0.74 & 0.83 & -0.51 & 0.91 & -0.59 & 0.84 \\
\hline SL & -0.62 & 0.77 & -0.74 & 0.80 & -0.59 & 0.65 & -0.66 & 0.81 \\
\hline SM & -0.72 & 0.76 & -0.50 & 0.74 & -0.32 & 0.67 & -0.38 & 0.56 \\
\hline $\mathrm{SH}$ & - & - & - & - & - & - & - & - \\
\hline
\end{tabular}

Table 2. Same as Table 1, but for stations over oceans.

\begin{tabular}{|c|c|c|c|c|c|c|c|c|}
\hline \multirow{2}{*}{ Latitude Zone (Ocean) } & \multicolumn{2}{|c|}{ December-February (DJF) } & \multicolumn{2}{|c|}{ March-May (MAM) } & \multicolumn{2}{|c|}{ June-August (JJA) } & \multicolumn{2}{|c|}{ September-November (SON) } \\
\hline & $R H$ & $T_{\mathrm{sfc}}$ & $R H$ & $T_{\mathrm{sfc}}$ & $R H$ & $T_{\mathrm{sfc}}$ & $R H$ & $T_{\mathrm{sfc}}$ \\
\hline EN & -0.83 & 0.87 & -0.85 & 0.89 & -0.57 & 0.70 & -0.84 & 0.86 \\
\hline NM & -0.77 & 0.52 & -0.88 & 0.77 & -0.81 & 0.70 & -0.82 & 0.83 \\
\hline $\mathrm{NH}$ & 0.84 & 0.43 & -0.33 & 0.55 & -0.52 & 0.45 & 0.05 & 0.50 \\
\hline SL & -0.55 & 0.61 & -0.47 & 0.45 & -0.15 & 0.60 & -0.62 & 0.74 \\
\hline SM & -0.82 & 0.79 & -0.85 & 0.73 & -0.91 & 0.46 & -0.86 & 0.78 \\
\hline $\mathrm{SH}$ & -0.53 & 0.77 & -0.16 & 0.04 & 0.08 & 0.10 & -0.44 & 0.56 \\
\hline
\end{tabular}



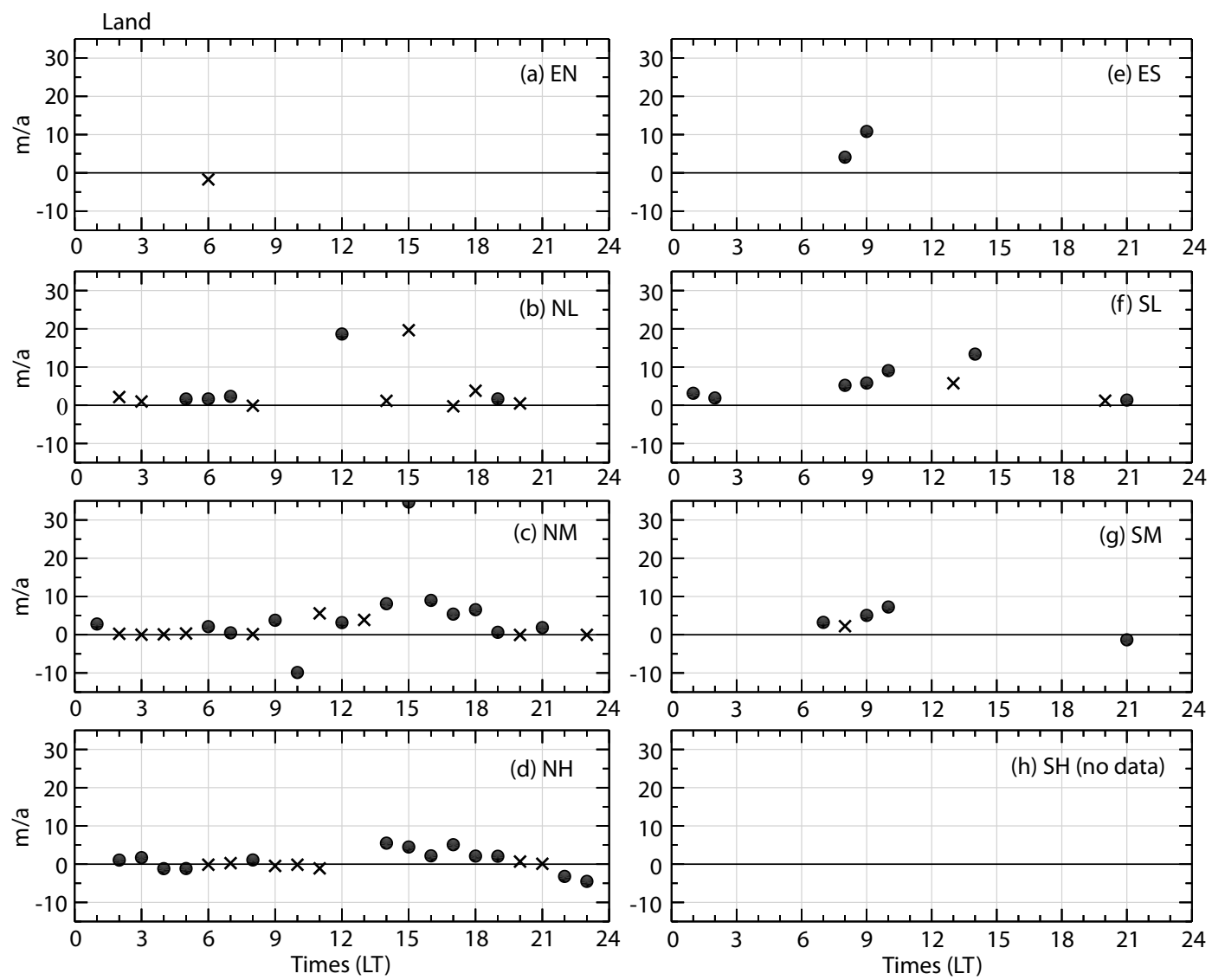

Figure 10. Trends of median PBLH over land at all 24 hours over the 45 -year period from 1973 to 2017 in the Northern (a, b, c, d) and Southern $(e, f, g, h)$ Hemispheres. Solid circles indicate that trends are significant at the $95 \%$ confidence level or greater.

$\mathrm{m} \cdot \mathrm{a}^{-1}$. The trends of daytime PBLH in the NM regions are slightly larger than those in the $\mathrm{NH}$ regions. The increasing trend in the daytime PBLH is consistent with the results from Zhang YH et al. (2013) for Europe. The daytime PBLHs over ocean, compared to those over land, are increasing with a greater statistical significance, not only in the Northern Hemisphere but also the Southern Hemisphere; in the NM region, the maximum increasing trend occurs, as above land, at 15:00 LT, at a rate of about $16.0 \mathrm{~m} \cdot \mathrm{a}^{-1}$, which is much lower than that of the increase over land. Figure 12 presents a map of the PBLH trend at 12:00 UTC from 1973 to 2017 at each station. Symbols outlined in thick black lines indicate values that are statistically significant at the $95 \%$ confidence level or greater. The local time at each station is shown at the bottom. Data from most stations in the daytime confirm that the 12:00 UTC PBLH exhibits an increasing trend over these years. The map of the 00:00 UTC PBLH trend shows a similar pattern: no obvious trend found at those stations at night but increasing trends consistently found at those stations in the daytime. The increases of daytime PBLH may be associated with the increases of near-surface temperature and decreases of near-surface relative humidity. However, according to the previous literatures (Bates and Jackson, 2001; Santer et al., 2014; Rinke et al., 2019), the trends in the tropospheric temperature and humidity might be different at regional scale. In addition, the increase of greenhouse gases and soil moisture heterogeneity might also be contributing to the observed increasing trend. Therefore, the detailed mechanisms driving increases in daytime PBLHs need further investigation.

\section{Conclusion}

In this paper, global diurnal variations in the PBLH at different latitudes over two surface characteristics (land and ocean) based on radiosonde observations from 1973 to 2017 are investigated. We use the BRN method to estimate boundary layer height, and compare the results with those of the parcel method and of the potential temperature gradient method. In general, the BRN method is found to represent satisfactorily the height of the CBL and NRL cases, but to have a relatively large uncertainty in the SBL cases.

The global patterns of median PBLHs at 00:00 UTC and 12:00 UTC respectively, are consistent with results derived from reanalysis of the ECMWF data by Von Engeln and Teixeira (2013), as well as with regional results over the US and Europe reported by Seidel et al. (2012). The PBLH is high at those stations where observational times are around noon and stays low at night. In addition, the PBLH decreases poleward in the daytime.

Regarding the diurnal variations in the global PBLH, we studied 8 regions: high latitudes $\left(\mathrm{NH}: 60^{\circ} \mathrm{N}-70^{\circ} \mathrm{N}, \mathrm{SH}: 60^{\circ} \mathrm{S}-70^{\circ} \mathrm{S}\right)$, middle latitudes (NM: $30^{\circ} \mathrm{N}-40^{\circ} \mathrm{N}, \mathrm{SM}: 30^{\circ} \mathrm{S}-40^{\circ} \mathrm{S}$ ), low latitudes ( $\mathrm{NL}$ : $\left.20^{\circ} \mathrm{N}-30^{\circ} \mathrm{N}, \mathrm{SL}: 20^{\circ} \mathrm{S}-30^{\circ} \mathrm{S}\right)$, and the equator (EN: $0^{\circ} \mathrm{N}-10^{\circ} \mathrm{N}$, ES: $\left.0^{\circ} \mathrm{S}-10^{\circ} \mathrm{S}\right)$ in the Northern Hemisphere $(\mathrm{N})$ and Southern Hemisphere (S) over two surface characteristics (land and ocean). In general, the diurnal cycles of the PBLH over land and over ocean are quite different. For stations over land, the PBLH shows an apparent diurnal cycle, with a distinct maximum around 15:00 LT; 

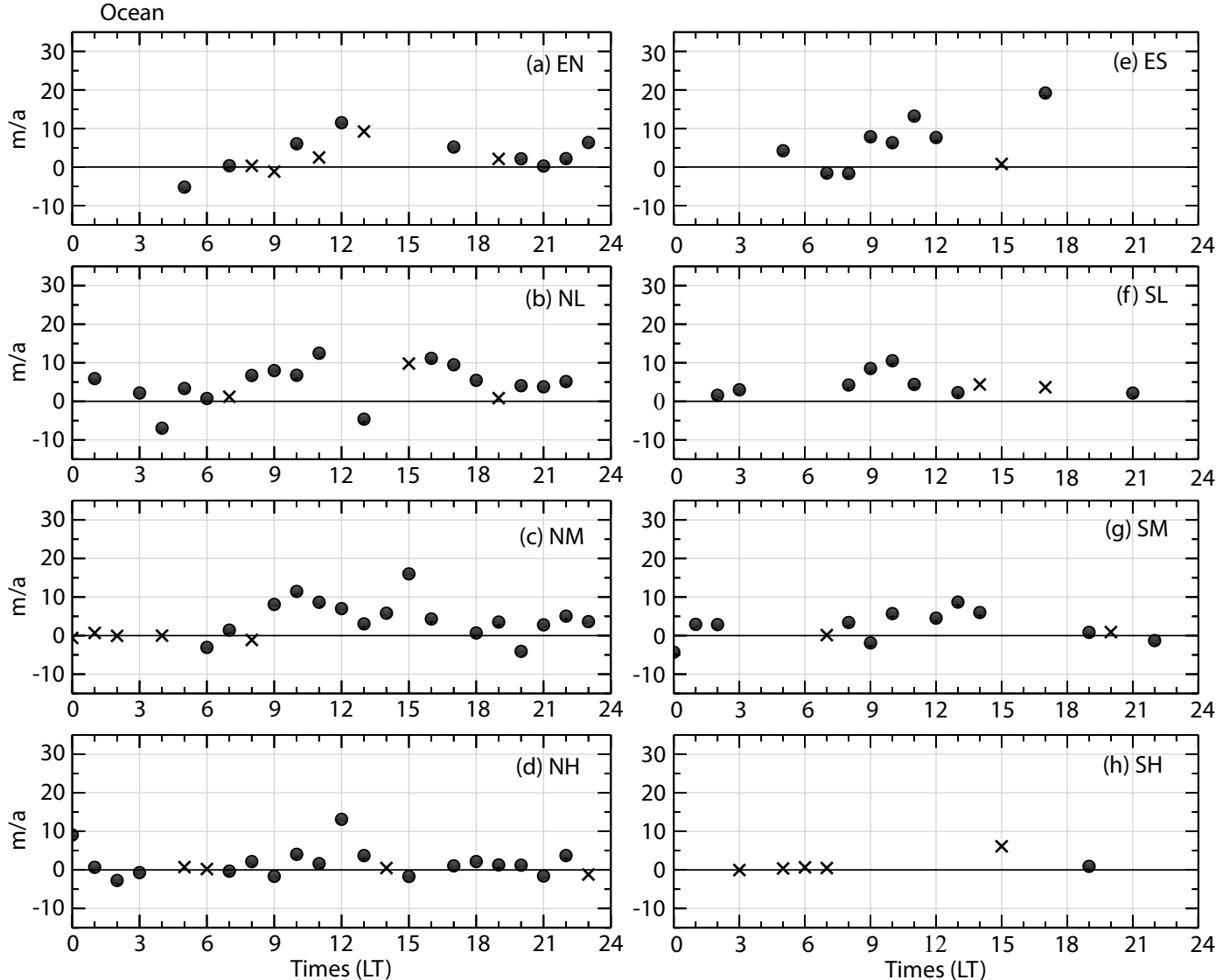

Figure 11. Same as Figure 10, but for stations over ocean.

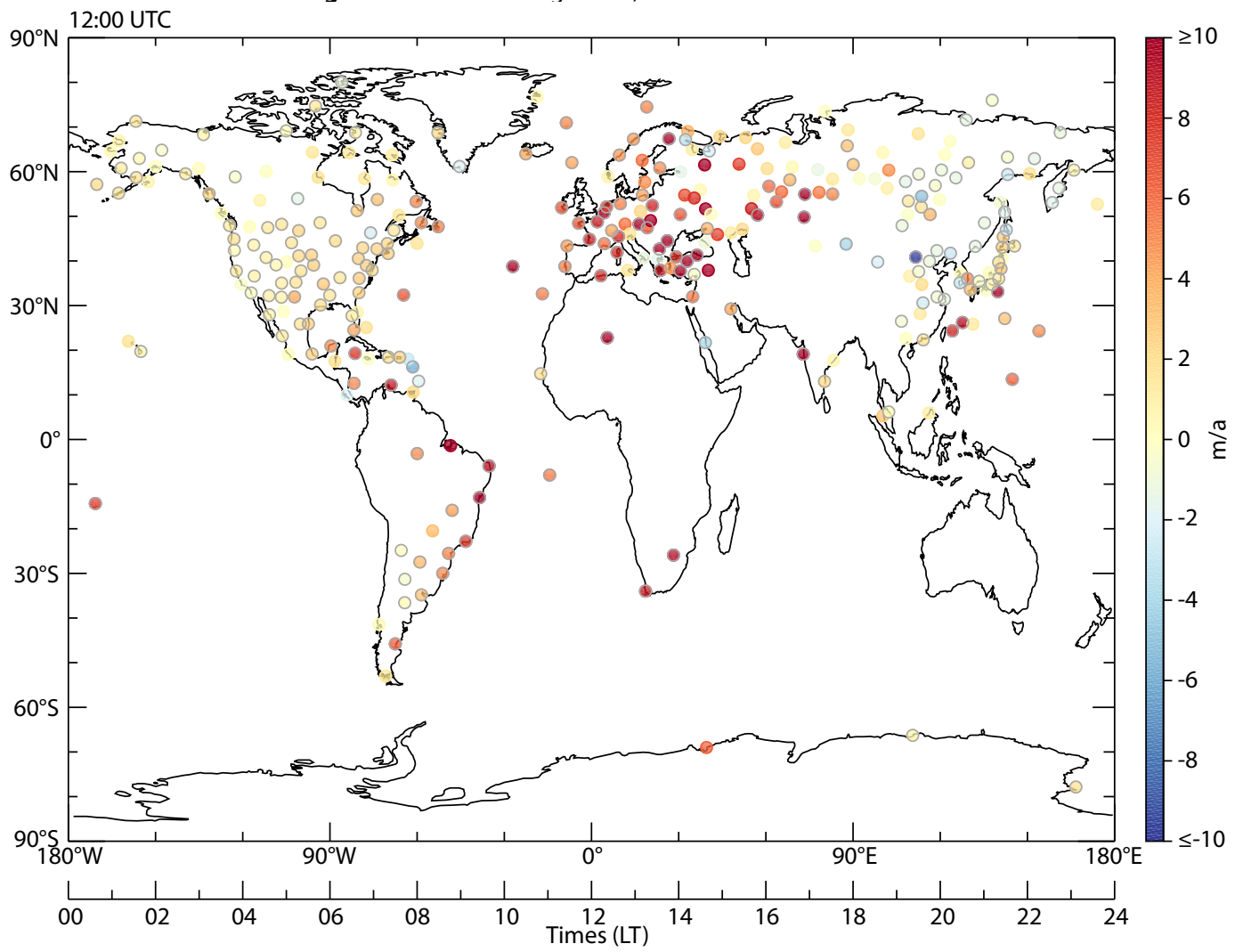

Figure 12. Map of the 12:00 UTC PBLH trend between 1973 and 2017 at each station. Symbols with thick black lines indicate that trends are significant at the $95 \%$ confidence level or greater. 
this conclusion is consistent with previous literature (Liu SY and Liang XZ, 2010; Chu YQ et al., 2019). In the Northern Hemisphere, the nighttime PBLH (from 19:00 LT to 07:00 LT) stays low $(<500 \mathrm{~m})$; the PBLH, rises slowly from 07:00 to 15:00 LT, and then falls relatively steeply from 15:00 to 19:00 LT (17:00 to 19:00 LT for the NM region), with values around noon that are generally higher than $1000 \mathrm{~m}$. As compared with land, the PBLHs over oceans are much lower and their diurnal cycles are quite mild.

The seasonal variations in the median PBLH diurnal cycles over land and ocean are different. In general, for both hemispheres, except for the areas around the equator, the daytime PBLH over land shows an apparent seasonal cycle, with higher values in summer and lower values in winter. Over oceans, however, the PBLHs in both hemispheres show less seasonal variation than over land, either in the daytime or at night, and the differences among the four seasons are relatively small for most studied regions, except for the high latitudes. The diurnal cycle in the median PBLH seems to have a close relationship with changes in the near-surface temperature and $\mathrm{RH}$. According to our correlation analysis, for most studied regions during the four seasons, on a daily scale lower near-surface $\mathrm{RH}$ s and higher temperatures appear to signal higher PBLHs. The large thermal capacity of oceans may explain to some extent the fact that the PBLH over oceans shows less seasonal variations than that over land. We note that data collected at most coastal and island stations will reflect more complicated physical processes that will influence the observed PBLH.

Trends in the median PBLH at all 24 hours over land and ocean were also studied. In general, there was no significant trend in the nighttime PBLH for almost all the studied latitudes over both land and ocean, which is consistent with findings of previous studies. In contrast, the daytime PBLH exhibits a statistically significant increasing trend at most hours between 12:00 LT and 18:00 LT over both land and oceans in most latitudes. The increasing trends over land are generally larger than those over ocean. Whatever the cause(s) of these trends toward increasing daytime PBLHs, natural factors or human activities, the trends are important and worthy of increased attention.

Radiosonde profiles have been a reference for other datasets, and the results of the PBLH diurnal cycle at different latitudes over different surface characteristics improve our understanding of the development processes of the PBL. Overall, our findings reveal that the diurnal variations in the PBLH are different from region to region and also different over land and oceans. Although associations with the near-surface temperature and humidity are discussed in this paper, further detailed analyses are still needed.

\section{Acknowledgments}

This work was supported by the Meteorological Research Open Foundation of Huaihe Basin (HRM20 1604). We are grateful to the National Climatic Data Center (NCDC) for providing observation data.

\section{References}

Ao, C. O., Waliser, D. E., Chan, S. K., Li, J. L., Tian, B. J., Xie, F. Q., and Mannucci, A. J. (2012). Planetary boundary layer heights from GPS radio occultation refractivity and humidity profiles. J. Geophys. Res.: Atmos., 117(D16), D16117. https://doi.org/10.1029/2012JD017598

Bates, J. J., and Jackson, D. L. (2001). Trends in upper-tropospheric humidity. Geophys. Res. Lett., 28(9), 1695-1698. https://doi.org/10.1029/2000GL012544

Beyrich, F. (1997). Mixing height estimation from SODAR data-A critical discussion. Atmos. Environ., 31(23), 3941-3953. https://doi.org/10.1016/S1352-2310(97)00231-8

Bissinger, K., and Bogner, F. X. (2018). Environmental literacy in practice: education on tropical rainforests and climate change. Environ. Dev. Sustain., 20(5), 2079-2094. https://doi.org/10.1007/s10668-017-9978-9

Chan, K. M., and Wood, R. (2013). The seasonal cycle of planetary boundary layer depth determined using COSMIC radio occultation data. J. Geophys. Res.: Atmos., 118(22), 12422-12434. https://doi.org/10.1002/2013JD020147

Cherfouh, R., Lucas, Y., Derridj, A., and Merdy, P. (2018). Long-term, low technicality sewage sludge amendment and irrigation with treated wastewater under Mediterranean climate: impact on agronomical soil quality. Environ. Sci. Pollut. Res., 25(35), 35571-35581.

https://doi.org/10.1007/s11356-018-3463-3

Chu, Y. Q., Li, J., Li, C. C., Tan, W. S., Su, T. N., and Li, J. (2019). Seasonal and diurnal variability of planetary boundary layer height in Beijing: Intercomparison between MPL and WRF results. Atmos. Res., 227, 1-13. https://doi.org/10.1016/j.atmosres.2019.04.017

Clifford, S. F., Kaimal, J. C., Lataitis, R. J., and Strauch, R. G. (1994). Ground-based remote profiling in atmospheric studies: An overview. Proc. IEEE, 82(3), 313-355. https://doi.org/10.1109/5.272138

Daher, D. H., Gaillard, L., Amara, M., and Ménézo, C. (2018). Impact of tropical desert maritime climate on the performance of a PV grid-connected power plant. Renew. Energy, 125, 729-737.

https://doi.org/10.1016/j.renene.2018.03.013

Durre, I., and Yin, X. G. (2008). Enhanced radiosonde data for studies of vertical structure. Bull. Amer. Meteor. Soc., 89(9), 1257-1261. https://doi.org/10.1175/2008BAMS2603.1

Durre, I., Vose, R. S., and Wuertz, D. B. (2006). Overview of the integrated global radiosonde archive. J. Climate, 19(1), 53-68. https://doi.org/10.1175/JCLI3594.1

Eresmaa, N., Karppinen, A., Joffre, S. M., Räsänen, J., and Talvitie, H. (2006). Mixing height determination by ceilometer. Atmos. Chem. Phys., 6(6), 1485-1493. https://doi.org/10.5194/acp-6-1485-2006

Guo, J. P., Miao, Y. C., Zhang, Y., Liu, H., Li, Z. Q., Zhang, W. C., He, J., Lou, M. Y., Yan, Y., ... Zhai, P. M. (2016). The climatology of planetary boundary layer height in China derived from radiosonde and reanalysis data. Atmos. Chem. Phys., 16(20), 13309-13319. https://doi.org/10.5194/acp-16-13309-2016

Guo, J. P., Su, T. N., Li, Z. Q., Miao, Y. C., Li, J., Liu, H., Xu, H., Cribb, M., and Zhai, P. $M$. (2017). Declining frequency of summertime local-scale precipitation over eastern China from 1970 to 2010 and its potential link to aerosols. Geophys. Res. Lett., 44(11), 5700-5708. https://doi.org/10.1002/2017GL073533

Guo, J. P., Li, Y., Cohen, J. B., Li, J., Chen, D. D., Xu, H., Liu, L., Yin, J. F., Hu, K. X., and Zhai, P. M. (2019). Shift in the temporal trend of boundary layer height in China using long-term (1979-2016) radiosonde data. Geophys. Res. Lett., 46(11), 6080-6089. https://doi.org/10.1029/2019GL082666

Jordan, N. S., Hoff, R. M., and Bacmeister, J. T. (2010). Validation of Goddard earth observing system-version 5 MERRA planetary boundary layer heights using CALIPSO. J. Geophys. Res. Atmos., 115(D24), D24218. https://doi.org/10.1029/2009JD013777

Lanzante, J. R. (1996). Resistant, robust and non-parametric techniques for the analysis of climate data: Theory and examples, including applications to historical radiosonde station data. Int. J. Climatol., 16(11), 1197-1226. https://doi.org/10.1002/(SICI) 1097-0088(199611)16:11<1197::AIDJOC89>3.0.CO;2-L

Li, Z. Q., Guo, J. P., Ding, A. J., Liao, H., Liu, J. J., Sun, Y., Wang, T. J., Xue, H. W., .. Zhu, B. (2017). Aerosol and boundary-layer interactions and impact on air quality. Natl. Sci. Rev., 4(6), 810-833. https://doi.org/10.1093/nsr/nwx117

Liu, B., Ma, Y. Y., Guo, J. P., Wei, G., Zhang, Y., Li, J., Guo, X. R., and Shi Y. F. (2019). Boundary Layer Height as derived from ground-based Radar wind profiler in Beijing. IEEE. T. Geosci. Remote., 57(10), 8095-8104. https://doi.org/10.1109/TGRS.2019.2918301 
Liu, L., Guo, J. P., Miao, Y. C., Liu, S., Li, J., Chen, D. D., He, J., and Cui, C. G. (2018). Elucidating the relationship between aerosol concentration and summertime boundary layer structure in central China. Environ. Pollut., 241, 646-653. https://doi.org/10.1016/j.envpol.2018.06.008

Liu, S. Y., and Liang, X. Z. (2010). Observed diurnal cycle climatology of planetary boundary layer height. J. Climate, 23(21), 5790-5809. https://doi.org/10.1175/2010JCLI3552.1

Liu, Y., Tang, N. J., and Yang, X. S. (2016). Height of atmospheric boundary layer as detected by COSMIC GPS radio occultation data. J. Trop. Meteor., 22(1), 74-82. https://doi.org/10.16555/j.1006-8775.2016.01.009

Molod, A., Salmun, H., and Dempsey, M. (2015). Estimating Planetary Boundary Layer Heights from NOAA Profiler Network Wind Profiler Data. J. Atmos. Ocean. Technol., 32(9), 1545-1561. https://doi.org/10.1175/JTECH-D-1400155.1

Norton, C. L., and Hoidale, G. B. (1976). The diurnal variation of mixing height by season over white sands missile range, New Mexico. Mon. Wea. Rev., 104(10), 1317-1320. https://doi.org/10.1175/1520-0493(1976)104<1317:tdvomh> 2.0.co; 2

Pavlov, A. V., and Pavlova, N. M. (2007). Anomalous night-time peaks in diurnal variations of $\mathrm{NmF} 2$ close to the geomagnetic equator: A statistical study. J. Atmos. Sol.-Terr. Phys., 69(15), 1871-1883. https://doi.org/10.1016/j.jastp.2007.07.003

Raval, A., and Ramanathan, V. (1989). Observational determination of the greenhouse effect. Nature, 342(6251), 758-761. https://doi.org/10.1038/342758a0

Rinke, A., Segger, B., Crewell, S., Maturilli, M., Naakka, T., Nygård, T., Vihma, T., Alshawaf, F., Dick, G., .... Keller, J. (2019). Trends of vertically integrated water vapor over the arctic during 1979-2016: Consistent moistening all over?. J. Climate, 32(18), 6097-6116. https://doi.org/10.1175/JCLI-D-190092.1

Santer, B. D., Bonfils, C., Painter, J. F., Zelinka, M. D., Mears, C., Solomon, S., Schmidt, G. A., Fyfe, J. C., Cole, J. N. S., ... Wentz, F. J. (2014). Volcanic contribution to decadal changes in tropospheric temperature. Nat. Geosci., 7(3), 185-189. https://doi.org/10.1038/ngeo2098

Seibert, P., Beyrich, F., Gryning, S. E., Joffre, S., Rasmussen, A., and Tercier, P. (2000). Review and intercomparison of operational methods for the determination of the mixing height. Atmos. Environ., 34(7), 1001-1027. https://doi.org/10.1016/s1352-2310(99)00349-0

Seidel, D. J., Zhang, Y. H., Beljaars, A., Golaz, J. C., Jacobson, A. R., and Medeiros, B. (2012). Climatology of the planetary boundary layer over the continental United States and Europe. J. Geophys. Res.: Atmos., 117(D17), D17106. https://doi.org/10.1029/2012JD018143
Stull, R. B. (1988). An Introduction to Boundary Layer Meteorology. Dordrecht: Springer. https://doi.org/10.1007/978-94-009-3027-8

Su, T. N., Li, J., Li, C. C., Xiang, P. Z., Lau, A. K. H., Guo, J. P., Yang, D. W., And Miao, Y. C. (2017). An intercomparison of long-term planetary boundary layer heights retrieved from CALIPSO, ground-based lidar, and radiosonde measurements over Hong Kong. J. Geophys. Res.: Atmos., 122(7), 3929-3943. https://doi.org/10.1002/2016JD025937

Tang, X. G., Li, H. P., Ma, M. G., Yao, L., Peichl, M., Arain, A., Xu, X. B., and Goulden, M. (2017). How do disturbances and climate effects on carbon and water fluxes differ between multi-aged and even-aged coniferous forests?. Sci. Total Environ., 599-600, 1583-1597. https://doi.org/10.1016/j.scitotenv.2017.05.119

Vogelezang, D. H. P., and Holtslag, A. A. M. (1996). Evaluation and model impacts of alternative boundary-layer height formulations. Bound.-Layer Meteor., 81(3-4), 245-269. https://doi.org/10.1007/bf02430331

Von Engeln, A., and Teixeira, J. (2013). A planetary boundary layer height climatology derived from ECMWF reanalysis data. J. Climate, 26(17), 6575-6590. https://doi.org/10.1175/JCLI-D-12-00385.1

Wang, X. Y., and Wang, K. C. (2016). Homogenized variability of radiosondederived atmospheric boundary layer height over the global land surface from 1973 to 2014. J. Climate, 29(19), 6893-6908. https://doi.org/10.1175/JCLI-D-15-0766.1

Wulfmeyer, V., Behrendt, A., Kottmeier, C., Corsmeier, U., Barthlott, C., Craig, G. C., Hagen, M., Althausen, D., Aoshima, F., ... Wirth, M. (2011). The convective and orographically-induced precipitation study (COPS): the scientific strategy, the field phase, and research highlights. Quart. J. Roy. Meteor. Soc., 137(S1), 3-30. https://doi.org/10.1002/qj.752

Zhang, W. C., Guo, J. P., Miao, Y. C., Liu, H., Zhang, Y., Li, Z. Q., and Zhai, P. M. (2016). Planetary boundary layer height from CALIOP compared to radiosonde over China. Atmos. Chem. Phys., 16(15), 9951-9963. https://doi.org/10.5194/acp-2016-250

Zhang, Y. H., Seidel, D. J., and Zhang, S. D. (2013). Trends in planetary boundary layer height over Europe. J. Climate, 26(24), 10071-10076. https://doi.org/10.1175/JCLI-D-13-00108.1

Zhang, Y. H., Zhang, S. D., Huang, C. M., Huang, K. M., Gong, Y., and Gan, Q. (2014). Diurnal variations of the planetary boundary layer height estimated from intensive radiosonde observations over Yichang, China. Sci. China Technol. Sci., 57(11), 2172-2176. https://doi.org/10.1007/s11431-014-5639-5

Zhang, Y. H., and Li, S. Y. (2019). Climatological characteristics of planetary boundary layer height over Japan. Int. J. Climatol., 39(10), 4015-4028. https://doi.org/10.1002/joc.6056 